Archaeological Prospection

Archaeol. Prospect. 9999, (2016)

Published online in Wiley Online Library

(wileyonlinelibrary.com) DOI: 10.1002/arp.1549

\title{
Searching for the Antigonea Theatre: A Magnetic Survey in an Ancient Epirus City
}

\section{ANTONIO SCHETTINO ${ }^{1 *}$, DHIMITER CONDI ${ }^{2}$, ROBERTO PERNA ${ }^{3}$, PIETRO PAOLO PIERANTONI ${ }^{1}$ AND ANNNALISA GHEZZI ${ }^{4}$}

\author{
1 School of Science and Technology - Geology Division, University of Camerino, , Via Gentile III da Varano, \\ 62032 Camerino, (MC), Italy \\ 2 Albanian Institute of Archaeology, Tirana, Albania \\ ${ }^{3}$ Universitá degli Studi di Macerata - Dipartimento di Scienze Archeologiche e Storiche dell'Antichitá, \\ Macerata, (MC), Italy \\ ${ }^{4}$ Istituto di Istruzione Superiore 'Enrico Mattei', Recanati, Italy
}

ABSTRACT We report on two magnetic surveys performed in July and September 2015 at the ancient Hellenistic city of Antigonea, located in southern Albania. The main objective of the two surveys was to find the city theatre and determine possible sites of future excavations. We suggest a new technique for dense collecting of magnetic data along difficult terrains, with minimization of the topographic effect. Evidence of a possible location of the theatre was found along the southern slope of the Jermë hill, just outside the city walls. Other interesting structures indicate the presence of many other buildings in this part of the Antigonea settlement. Copyright @ 2016 John Wiley \& Sons, Ltd.

Key words: Magnetic anomalies; topographic correction; Greek theatre; Albania; Antigonea; filtering

\section{Introduction}

In July 2015, we started a high-resolution magnetic survey in the area of Gjirokastër, southern Albania, in support of a series of archaeological excavations and studies, conducted by the Albanian Institute of Archaeology and by the University of Macerata, that were being performed at the Roman settlement of Hadrianopolis and in the Drino Valley in the context of a Adriatic cross-border research programme for the study and valorization of the archaeological heritage (Perna and Çondi, 2012; Perna, 2013; Perna and Çondi, 2014a, 2014b; Figure 1). We report on the results of that mission separately. On that occasion, we had the opportunity to extend our work to the nearby Hellenistic city of Antigonea, situated at $600 \mathrm{~m}$ altitude on the hill of Jermë along the eastern side of the Drino Valley, whose decline is considered to be contemporary with

* Correspondence to: A. Schettino, University of Camerino, School of Science and Technology - Geology Division, Via Gentile III da Varano, 62032 Camerino (MC), Italy. E-mail: antonio. schettino@unicam.it the rise of the valley settlement of Hadrianopolis. Extensive excavations have been performed at Antigonea since the 1960s by the Albanian archaeologist Dhimosten Budina and continued to the present day by other Albanian and Greek archaeologists (Budina, 1976; Zachos et al., 2006; Çondi, 2014, and references cited therein). Although these studies led to the determination of the city layout, including most of its public area, the theatre was found neither during excavations nor after the latest topographic researches (Perna and Çondi, 2014a, 2014b). Therefore, we decided to focus on searching the potential location of a monumental theatre. Although the limited amount of available time did not allow an extensive survey along the $\sim 35$ ha settlement area, only a few areas with appropriate morphology existed, which could accommodate a Hellenistic theatre.

It is well-known that theatres of the ancient Hellenistic world were built within or close to the urban centres of cities along concavo-concave hill slopes on the basis of a specific acoustic design (e.g. Frederiksen, 2000). At Antigonea, only two nearby sites along the southern side of the Jermë hill allowed 


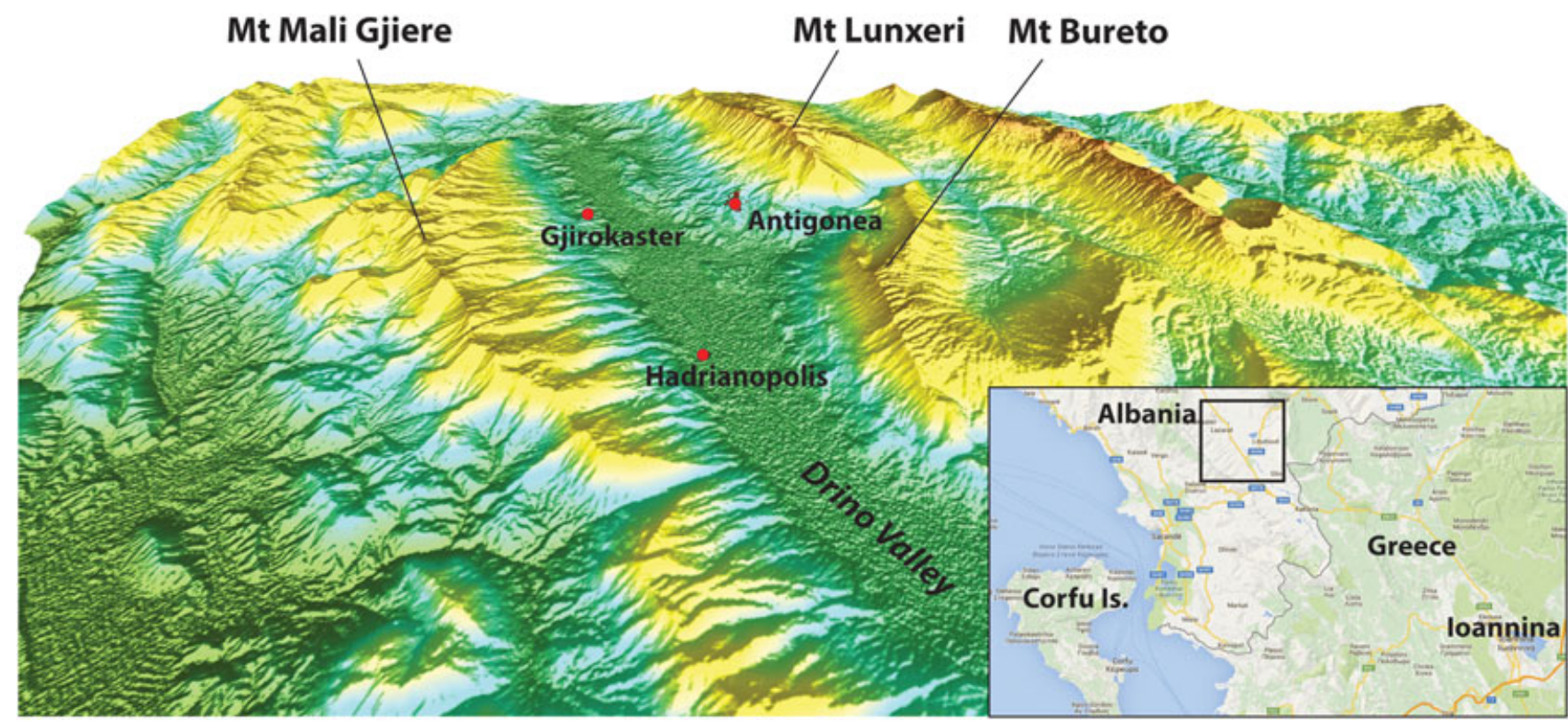

Figure 1. Location map of the study area, showing a perspective view of the Drino Valley and surrounding relief from USGS ASTER-GDEM data. Inset shows the Greece-Albania boundary zone of Epirus. The black box is the study area.

accommodation of a Greek theatre, because of their width, dip angle, and orientation. For example, it is known that the dip of canonical theatre koilons are always between $20^{\circ}$ and $30^{\circ}$, so that the present day hill slope should not exceed $30^{\circ}$. In addition, southward or eastward facing theatres seem to be preferred with respect to other orientations. Therefore, excluding the very steep eastern side of the Jermë hill and a very small and quite steep concave slope along the western side, we were left with two alternatives along the southern hill side, both characterized by a spectacular view of the Drino valley. We investigated the eastern slope on July 2015, and came back to the study area in September to survey the western slope.

A major problem with land magnetic surveys along mountain slopes and rugged terrain regions arises from the difficulty in applying high-resolution mapping survey techniques, which are, notwithstanding, of paramount importance in archaeological applications of geophysics. In addition, this class of surveys requires that one must take into account the lateral variations of burial depth of archaeological features, determined by lateral changes in the rate of erosion or accumulation along any arbitrary survey line. These variations generate magnetic anomaly field changes not associated with real variations of magnetic susceptibility or remnant magnetization. To deal with these problems, we developed a specific survey design, which could be also applied in other situations.
In this paper, we report on the results of two magnetic surveys performed along the southern side of the Jermë hill with the objective of locating the Antigonea theatre. We shall prove that the eastern one of these slopes could be the locus of a monumental Hellenistic theatre, whereas the western slope seems to accommodate other buildings. The new surveying technique seems to be effective in minimizing topographic effects while allowing a sufficient spatial resolution. Therefore, it could be applied to other complex archaeological contexts.

\section{Historical background}

The city of Antigonea stands on the top of the hill of Jermë, near the village of Saraqinishte. The archaeological investigations of Budina between 1960 and 1980 identified the site and its name, also thanks to the discovery of a series of bronze tesserae with the inscription ANTIГONE $\Omega N$. The latest investigations at this site, which were conducted by Çondi (2014), provided important information about the urban organization of the city.

Antigonea was founded by Pyrrhus between 297 and 295 BC at a site where earlier occupation is not excluded, with the aim of controlling the territory and the routes along the Drino valley. The city 
occupies a large triangular plateau, while the northern hill served as the acropolis. The fortified walls, with double curtain in opera poligonale and quadrata, with a thickness of $3.5 \mathrm{~m}$ and $\sim 4000 \mathrm{~m}$ length, protected an area of about 35 ha, reaching, at the highest conserved point, the height of $3 \mathrm{~m}$. The walls had three gateways, of which the southern one was monumental, and 13 monumental towers of quadrangular shape. The acropolis was enclosed in a fortified system and was separated by diatechismata equipped with towers.

The two main roads that have been identified within the city intersect orthogonally and are paved by stones of medium and small size. The settlement was organized on the basis of a regular urban plan and arranged by narrow and long blocks of different size, adapted to the difficult terrain through terracing, above which the public and residential districts were built. The residential neighbourhoods are characterized by four different types of houses, all being organized around courtyards. The houses, constructed from perishable material on a base of stone, can be dated back to the third and second centuries BC.

The excavations yielded a great quantity of pottery and metal artefacts, suggesting that handicrafts played an important role in the economic life of the city. A decisive role was covered by agriculture and farms. The high number of coins found, most of them belonging to the League of Epirus, documents that in the third and in the second century BC Antigonea became an important commercial centre. The high level of development achieved in the third and second centuries $\mathrm{BC}$ is directly related to the strategic position of the city, which controlled the valley of Drino. Its location was defensible in the middle of a territory that, within the koinón of Epirotes and under the control of the Molossian kingdom, was organized like that of a Greek polis, with a series of fortresses that protected the access (Perna and Çondi, 2014a, 2014b; Perna, 2015).

Antigonea was severely damaged at the end of the first half of the second century BC, perhaps by a devastating fire in retaliation of the partisans of Perseus during the third Macedonian War. Starting from this time, the city was gradually abandoned, simultaneously to the development of urban centres along the plains, more adapted to the new Roman policy that provided a systematic exploitation of the agricultural valley. It is no coincidence that on the bottom of the valley of Drino Hadrianopolis sprang out and replaced Antigonea in the function of hegemonic centre for the territory. Even if the city lost its central role, we cannot say that the area was completely abandoned. In 1973, some archaeological investigations at the top of the hill of Saint Mehilli discovered traces of occupation of the territory after the Roman presence. Traces of later reuse of the settlement have also emerged within the 'Macedonian' burial. In any case, from the end of the fifth century AD the city, like other towns in the valley of Drino, hosted a settlement. This is documented, within the same walls, by a triconch church with mosaic floor dating between fifth and sixth centuries $A D$ (Mitchell, 2006).

\section{Geological setting}

As mentioned earlier, the archaeological site of Antigonea is located at $600 \mathrm{~m}$ altitude on the hill of Jermë along the valley of the Drino River in the Gjirokastër District, southern Albania. This is a tectonically active area, characterized by relatively high rate of seismic moment release and by potentially destructive earthquakes. The mountains surrounding the valley are part of the Albanides, which form together with the Dinarides to the north and the Hellenides to the south the southern branch of the Mediterranean Alpine belt. The sedimentary succession of this area starts with Permian-Triassic evaporites that are covered by thick deposits of upper Triassic-lower Jurassic dolomitic limestone and Jurassic-Paleogene pelagic cherty limestones. These limestones, in turn, are covered unconformably by Paleogene-Miocene flysch deposits that mark the onset of the Oligocene compressional regime. During the early Pliocene ( $4.5 \mathrm{Ma})$, the area emerged and the surrounding carbonate platforms were subject to severe erosion, with production along the slopes of thick scree and talus deposits (Meço and Aliaj, 2000, and references cited therein). Talus deposits typically have a concavo-concave shape, with a maximum inclination corresponding to the angle of repose of the mean debris size.

The city of Antigonea was founded on a wide outcrop of slope deposits and travertines along a lowangle slope linking Mount Lunxheri to the Drino Valley (Figure 2). The highest part of the city has an elevation of $650 \mathrm{~m}$, while the lowest part is located at $570 \mathrm{~m}$. These deposits have variable grain size and are well cemented, with clasts that are very angular to slightly rounded. Sometimes, these deposits are associated with travertines that developed along mineral springs, with a thickness that may reach $40-50 \mathrm{~m}$ (upper Pliocene-Quaternary). The topsoil that formed on these limestone deposits is represented by red soils, which developed under Mediterranean climate conditions (Yaalon, 1997). The magnetic susceptibility of this Terra Rossa soil is quite high and governed by the 


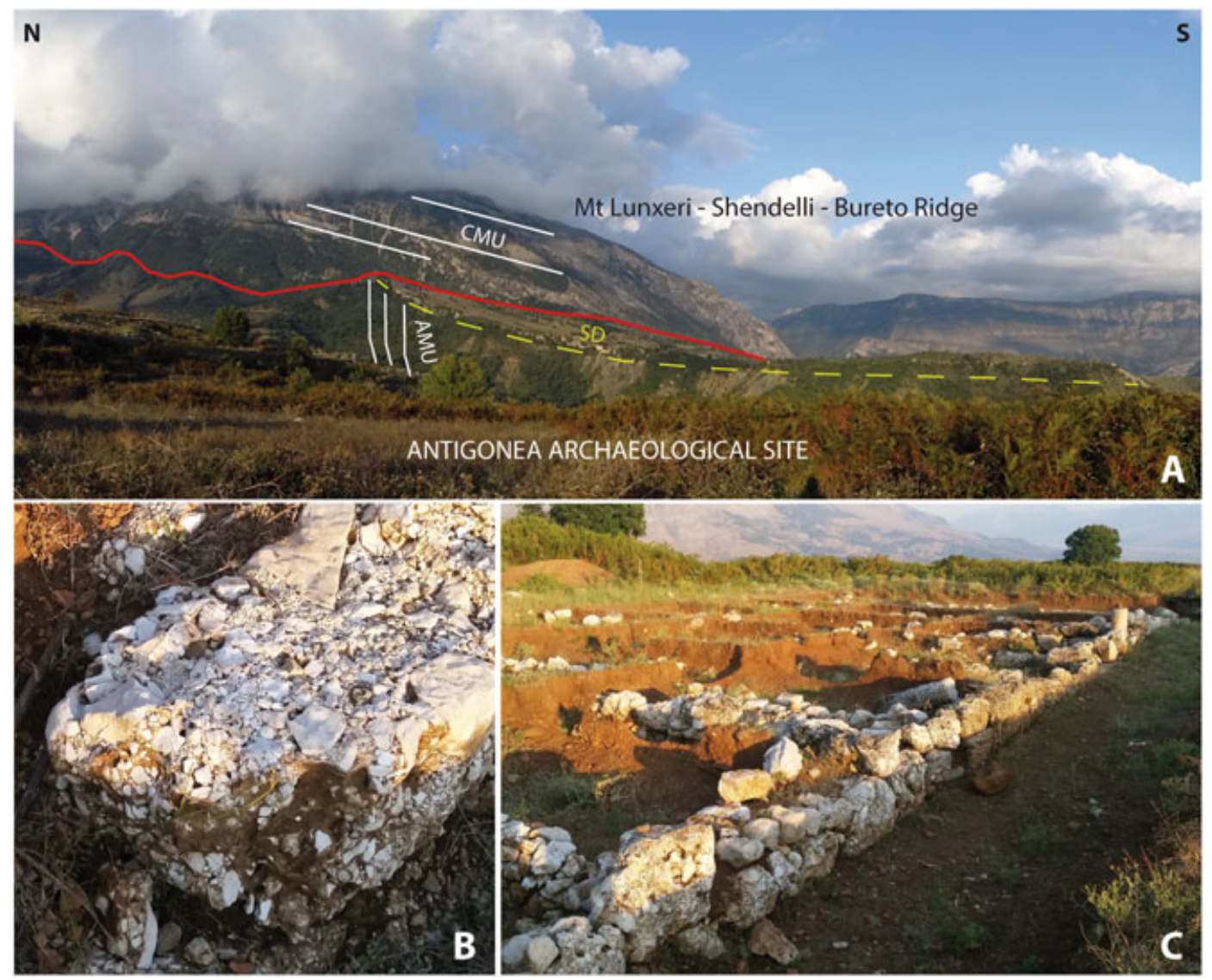

Figure 2. Geological setting of the Antigonea archaeological site. (A) High-angle tectonic contact (red line) between the upper Triassic-Eocene limestones of Mount Lunxeri (CMU) and sub-vertical arenaceous-marly Oligocene-lower Miocene deposits (AMU). The city of Antigonea was founded on a wide outcrop of slope deposits and travertines (SD) that cover the terrigenous deposits. (B) Scree and talus deposits with variable grain size, heterometric and well cemented; the clasts are very angular to little rounded (upper Pliocene-Quaternary). (C) Wall structures of the ancient city of Antigonea are embedded in Terra Rossa soil, which is the typical topsoil of Antigonea.

concentration of pedogenically produced singledomain and ultrafine superparamagnetic grains and haematite. According to Hannam and Dearing (2008), the mass susceptibility of Terra Rossa toposoil in the more northern areas of Bosnia and Herzegovina ranges between 118 and $474 \times 10^{-8} \mathrm{~m}^{3} \mathrm{~kg}^{-1}$, with an average of $294.5 \times 10^{-8} \mathrm{~m}^{3} \mathrm{~kg}^{-1}$. More generally, Tite and Linington (1975) found values ranging between 150 and $600 \times 10^{-8}$ $\mathrm{m}^{3} \mathrm{~kg}^{-1}$ for the whole Mediterranean region. Therefore, we expected that the high magnetic susceptibility of this topsoil would have resulted into elevated magnitudes of the magnetic anomaly field.

\section{Methods}

Total field magnetic data were collected using a Geometrics G-858 caesium vapour magnetometer and a Tallysman global positioning system (GPS) receiver configured to use corrections transmitted by a satellite-based augmentation system (SBAS). The two concavo-concave slopes were divided into smaller areas to simplify the acquisition of magnetic data. They are shown in Figure 3. For five rectangular and almost planar regions (A, B, E, G, and $\mathrm{H})$, we used a standard high-resolution acquisition technique (Figure 4A). In this instance, the GPS receiver was used exclusively to determine corner location coordinates and associated confidence regions, whereas the magnetic data were acquired at $10 \mathrm{~Hz}$ frequency along bi-directional survey lines equally spaced $0.5 \mathrm{~m}$ in a local reference frame. At a typical operator velocity of $4 \mathrm{~km} \mathrm{~h}^{-1}$, such a sampling frequency translated into an average $11 \mathrm{~cm}$ distance between readings. To avoid distortion of the mapped survey during the georeferencing step, we designed a computer algorithm to calculate the bestfitting rigid transformation from local coordinates to UTM. This procedure determined the best-fit locations of the system of survey rectangles by weighted least squares minimization of corner location errors relative 


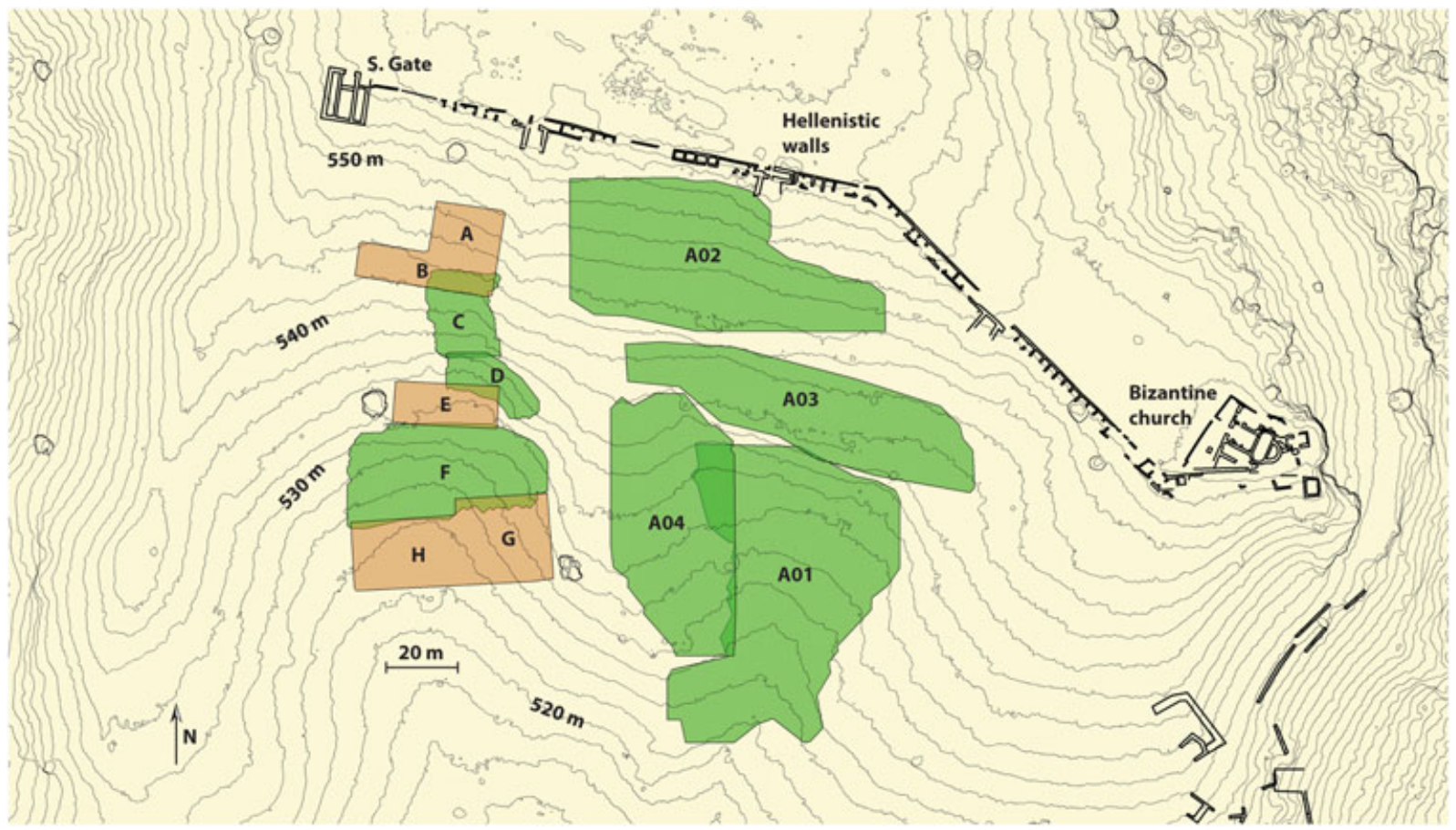

Figure 3. Sites of magnetic survey (A-H and A01-A04). Green areas indicate GPS-assisted measurements; bronze areas indicate high-resolution surveys. Black lines are exposed archaeological structures. Contour lines spaced $2 \mathrm{~m}$ apart show relief features in the surveyed area, in particular the two southward-directed concavo-concave areas of flow convergence (Shary et al., 2002).

to the measured GPS locations. The remaining nonplanar regions (A01, A02, A03, A04, C, D, and F) were investigated using GPS during walking. In this instance, we applied the method illustrated in Figure 4B to reduce the effect of topography on magnetic anomalies.

Let us consider the fate of a human artefact or building, originally located along a hill slope, after its destruction and razing to the ground. Potentially, this feature can generate a measurable magnetic anomaly according to its susceptibility contrast with respect to the topsoil, its shape, and the burial depth. Even materials having negligible susceptibility, such as most limestone rocks, can be detected because of their negative contrast of magnetization with respect to the surrounding settlement soil. However, because in this example the building remains are located along a hill slope, the burial depth will generally change from point to point according to the local rates of accumulation and erosion, which in turn depend from the local slope and slope values at points with higher altitude (e.g. Shary et al., 2002). In addition, even in the case of an approximately constant burial depth, which could be an appropriate assumption for a small feature, the distance of an observation point $P$ at horizontal offset $x$ from an arbitrary magnetized volume element of the buried feature, having surficial projection at point $Q$, will change considerably according to the strike of the segment $P Q$ (Figure $4 \mathrm{C}$ ). This distance will be maximum upslope and will attain its minimum in downslope direction. Consequently, a terrain effect is introduced in the resulting magnetic map, which may change dramatically the magnitude (and sometimes the sign) of the magnetic anomalies associated with buried features (e.g. Kangazian et al., 2015). In general, the amount of field distortion will depend on the terrain geometry, orientation, and steepness (Khesin et al., 1996; Eppelbaum et al., 2001).

To overcome at least in part this problem, we used a survey design that reduced both the effect of burial depth variability and the observed $\sim 13^{\circ}$ terrain slope. The method, which is illustrated in Figure 4B, is based on the reasonable assumption that points having the same orthometric height along a concavo-concave slope will experience approximately the same local accumulation/erosion rate. Hence, features located beneath these points should have the same burial rates through time. Furthermore, the magnitude of the anomaly amplification/contraction factor caused by the slope will be about the same along any contour line. These observations suggest that measurements performed along survey lines designed to be as close as possible to topographic contour lines will not be affected by significant distortion, thereby readings taken 


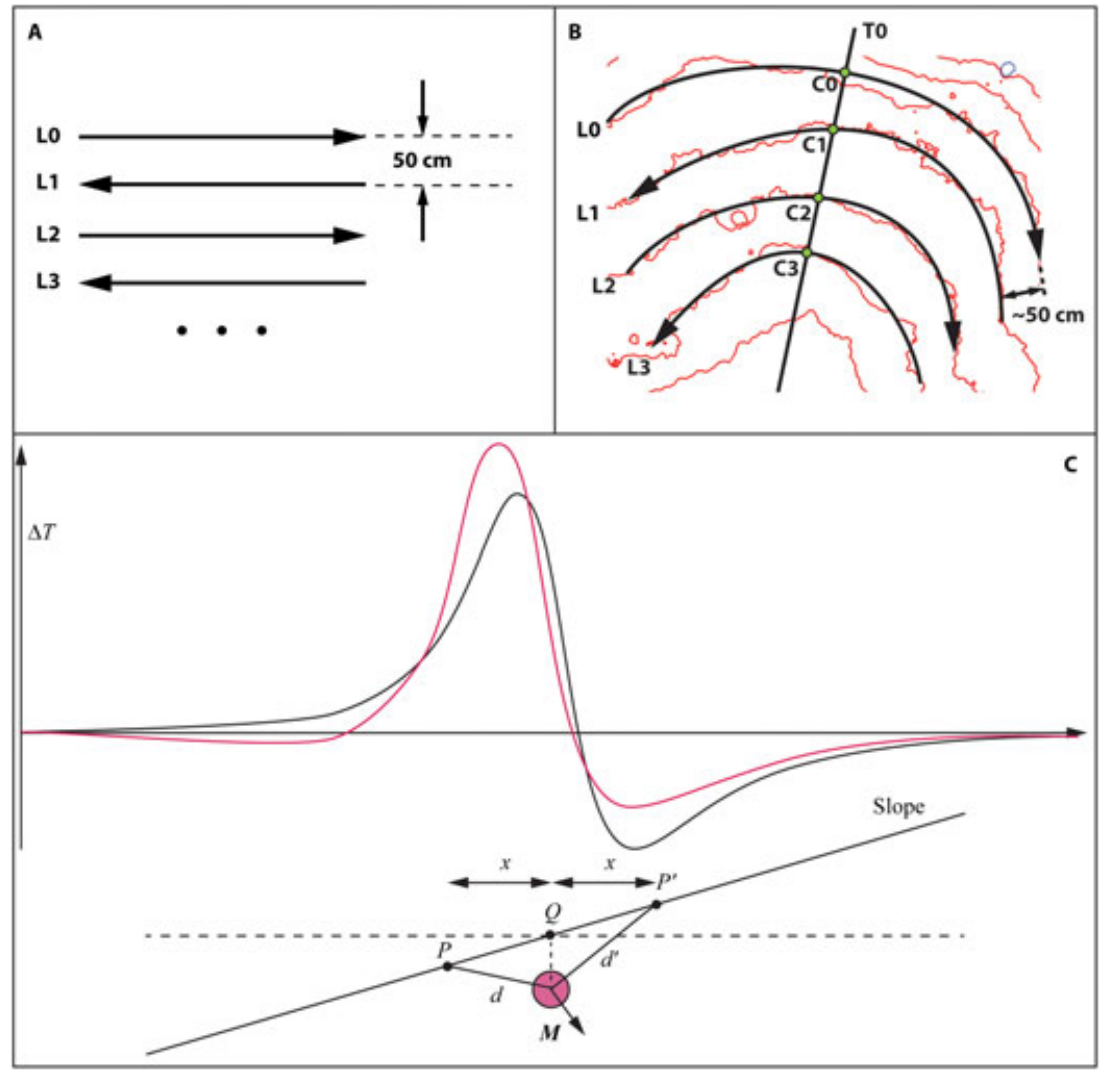

Figure 4. Survey pattern at Antigonea sites and terrain effect. $L i(i=0,1, \ldots)$ and Ti are, respectively, survey and tie lines (in black). (A) High-resolution mapped survey geometry at sites with sub-planar relief. (B) Pattern of GPS-assisted survey at sites with complex relief. Red lines are topographic contour lines. $\mathrm{Ci}(i=0,1, \ldots)$ are crossover points (green dots) for levelling. (C) Magnetic anomaly of a small buried feature (red line), observed along a downslope profile. The distance $d$ of an observation point $P$ from the dipole source $M$ is minimum in downslope direction. Therefore, in this example the magnitudes of the positive and negative peaks are increased and decreased, respectively, with respect to the curve that would be obtained along a horizontal profile (black line).

along these lines will be modified by the same amount. In this instance, a bi-directional gridding of the raw data should be sufficient to eliminate the topographic effect. This class of algorithms is appropriate for generating regular grids from survey data obtained along roughly parallel acquisition lines. The gridding procedure interpolated between the survey lines in the downslope direction using Akima splines. Therefore, it was able to enhance transverse (radial) features that extended from line to line perpendicularly to the slope contour lines.

All the total field survey measurements were done in solar-quiet conditions, with $\mathrm{Kp}$ index not exceeding 2. However, GPS-assisted surveys were performed at considerable slower velocity than standard highresolution mapped surveys. Therefore, in these instances we applied a levelling procedure, subtracting the estimated diurnal drift curve from the raw data. The diurnal drift curve was obtained from the intersection errors at crossover points (Figure 4B) by fitting a cubic polynomial. In all cases, the raw data were subject to standard pre-processing filtering (despiking and drop-out removal). In high-resolution mapped surveys (areas A, B, E, G, and H), the magnetic anomaly at any grid location $(x, y)$ was calculated by subtracting a third degree trend surface from the total field grid value $T(x, y)$ :

$$
\Delta T(x, y)=T(x, y)-\sum_{n, m=1}^{N} a_{n} b_{m} x^{n} y^{m}
$$

In Equation 1, $N=3$ and the coefficients $a_{n}$ and $b_{m}$ are determined by robust least-squares fitting over the field $T=T(x, y)$. Therefore, in this instance it is assumed that the superposition of Earth's core and crustal fields can be modelled by a third degree surface, so that the archaeological anomalies are defined as a zero-mean residual field about such a best-fitting trend surface. To justify this assumption, we note that the Earth's magnetic field is harmonic in the region outside the Earth's surface, thereby it has continuous derivatives. Consequently, in any sufficiently small survey area it 
can be represented by a Taylor's polynomial series with constant coefficients.

The calculation of magnetic anomalies was more complex for GPS-assisted surveys on rugged and steep terrain, because in this instance geological anomalies might have a short-wavelength component that interferes with archaeological anomalies. Therefore, we first determined raw anomalies, $\Delta T_{0}(x, y)$ by a standard procedure, i.e. subtracting the IGRF core field $F(x, y)$ from the total field measurements $T(x, y)$. The resulting data set included contributions from both regional-scale crustal magnetization and external fields in addition to archaeological anomalies. As mentioned earlier, we applied a levelling algorithm to remove the ionosphere/magnetosphere disturbing components from $\Delta T_{0}(x, y)$. The separation of archaeological anomalies $\Delta T(x, y)$ from the crustal field $\Delta T_{0}(x, y)$ was accomplished by the following expression:

$$
\Delta T(x, y)=\Delta T_{0}(x, y)-\sum_{n, m=1}^{N} a_{n} b_{m} x^{n} y^{m}
$$

where the coefficients $a_{n}$ and $b_{m}$ were determined again by robust least-squares regression. Differently from the high-resolution case, the degree $N$ of the trend surface in Equation 2 was estimated iteratively, assuming alternatively $N=3,4$, and 5 . We expected that increasing the degree of the regression polynomial surface would have decreased the standard deviation of the residuals to a value compatible with the signal produced by archaeological features buried in a Terra Rossa topsoil. We found that $N=3$ was a suitable value in the case of regions $\mathrm{C}, \mathrm{D}$, and $\mathrm{F}$, while calculation of anomalies for areas A01, A02, A03, and A04 required a higher value $N=5$.

\section{Results}

A three-dimensional (3D) view of the spatial distribution of the observed magnetic anomalies at sites $\mathrm{A}-\mathrm{H}$ and A01-A04 is shown in Figure 5. We note that the amplitude of the anomalies is higher along the eastern slope, where they have a standard deviation from the reference polynomial of $\sim 16.7 \mathrm{nT}$. In the western sector, the standard deviation results to be only $\sim 8.3 \mathrm{nT}$. Presumably, this difference is caused by the fact that the quite large areas A02 and A03 (Figure 3), close to the city walls, have high standard deviation, $19.9 \mathrm{nT}$ and $24.1 \mathrm{nT}$, respectively. Another striking feature of this distribution is that the western slope reveals the existence of two systems of anomalies, one formed by roughly north-south or east-west orientated buildings and the other one formed by northeast-southwest or northwest-southeast structures, while there is an apparently chaotic ensemble of buried features along the eastern slope. This could be indicative of two different kind of structures built along the two adjacent slopes. Detailed magnetic anomaly maps for the three separate sectors A02, A01-A03-A04, and A-H are illustrated in Figures 6,7 , and 8 , respectively. These maps also show

W

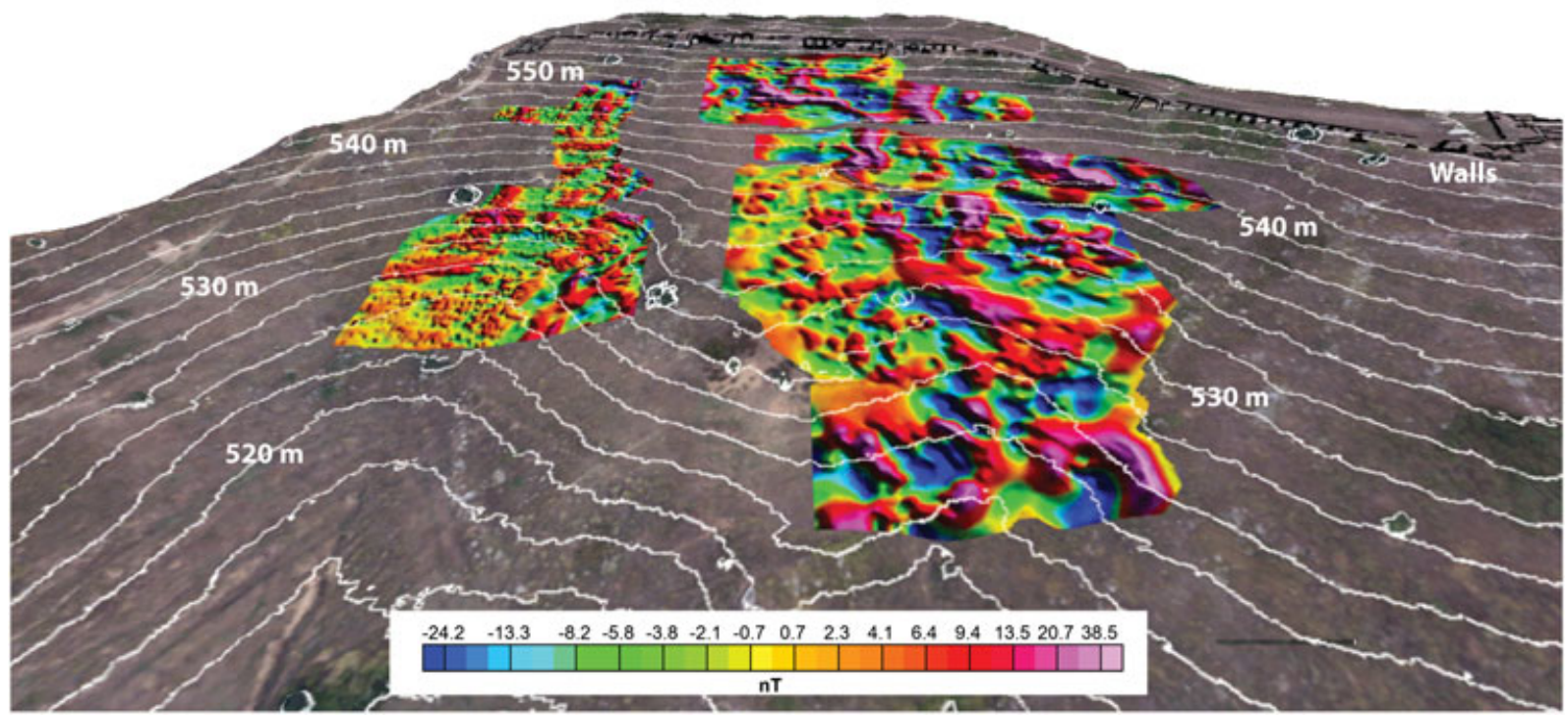

Figure 5. Magnetic anomaly map of sites A-H and A01-A04 on 3D relief map (view from the south). Contour lines are spaced $2 \mathrm{~m}$. 
A. Schettino et al.

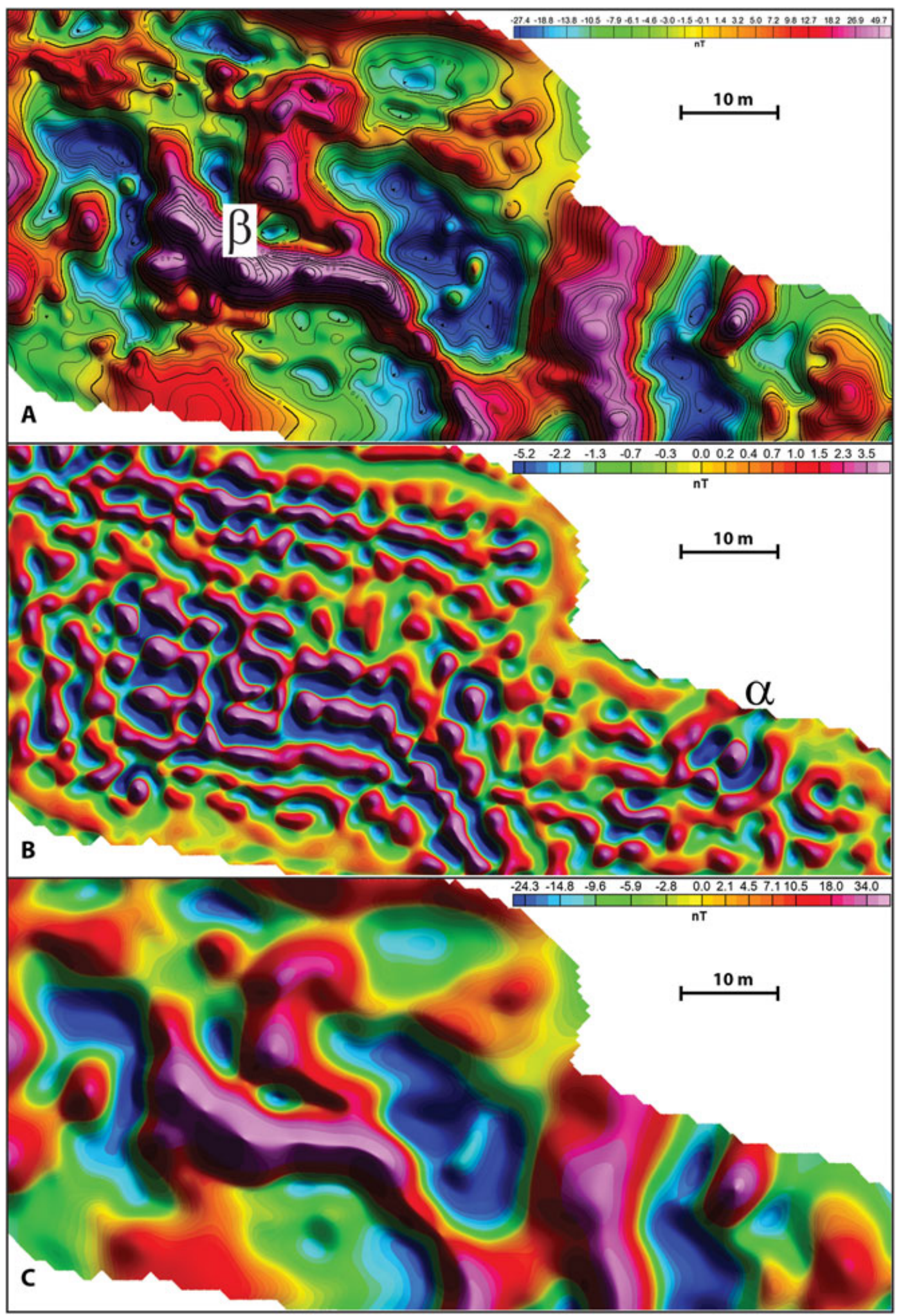

Figure 6. Magnetic anomaly map of site A02 (A). Panels (B) and (C) show the high-pass and low-pass filtered maps, respectively, with cutoff wavelength $\lambda \mathrm{c}=5 \mathrm{~m}$. 


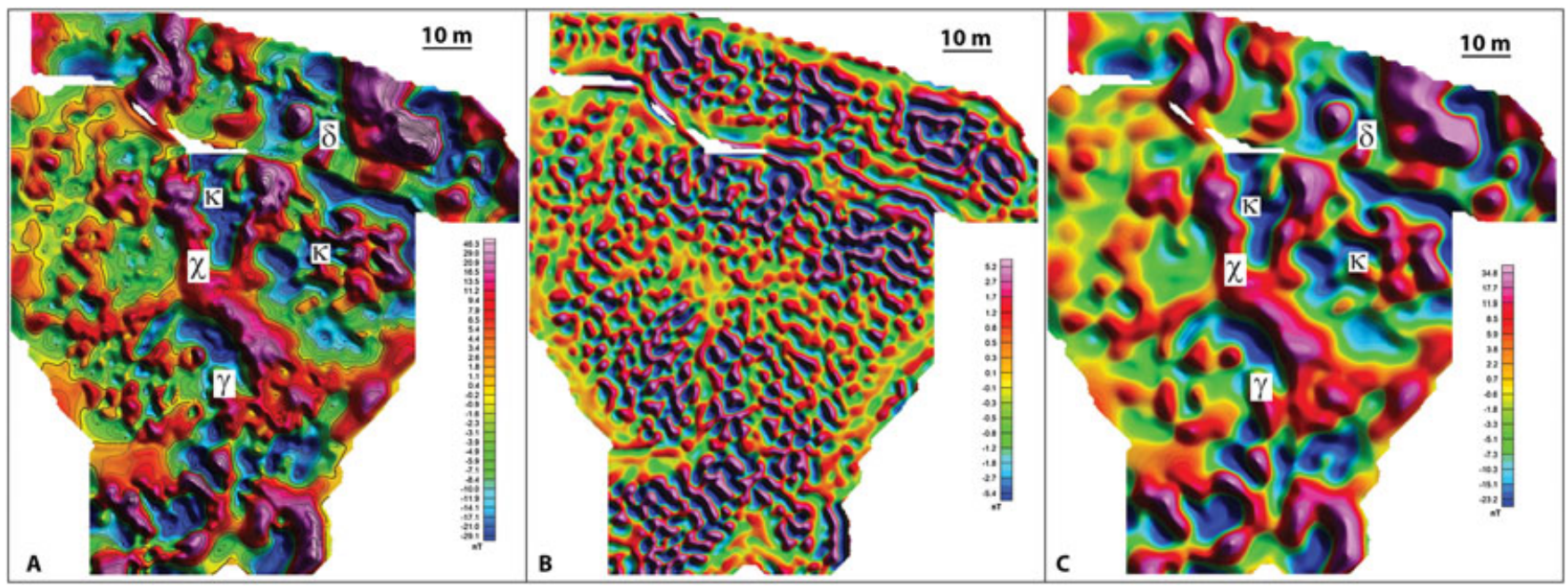

Figure 7. Combined magnetic anomaly map of sites A01-A03-A04 (A). Panels (B) and (C) show the high-pass and low-pass filtered maps, respectively, with cutoff wavelength $\lambda \mathrm{c}=5 \mathrm{~m}$.

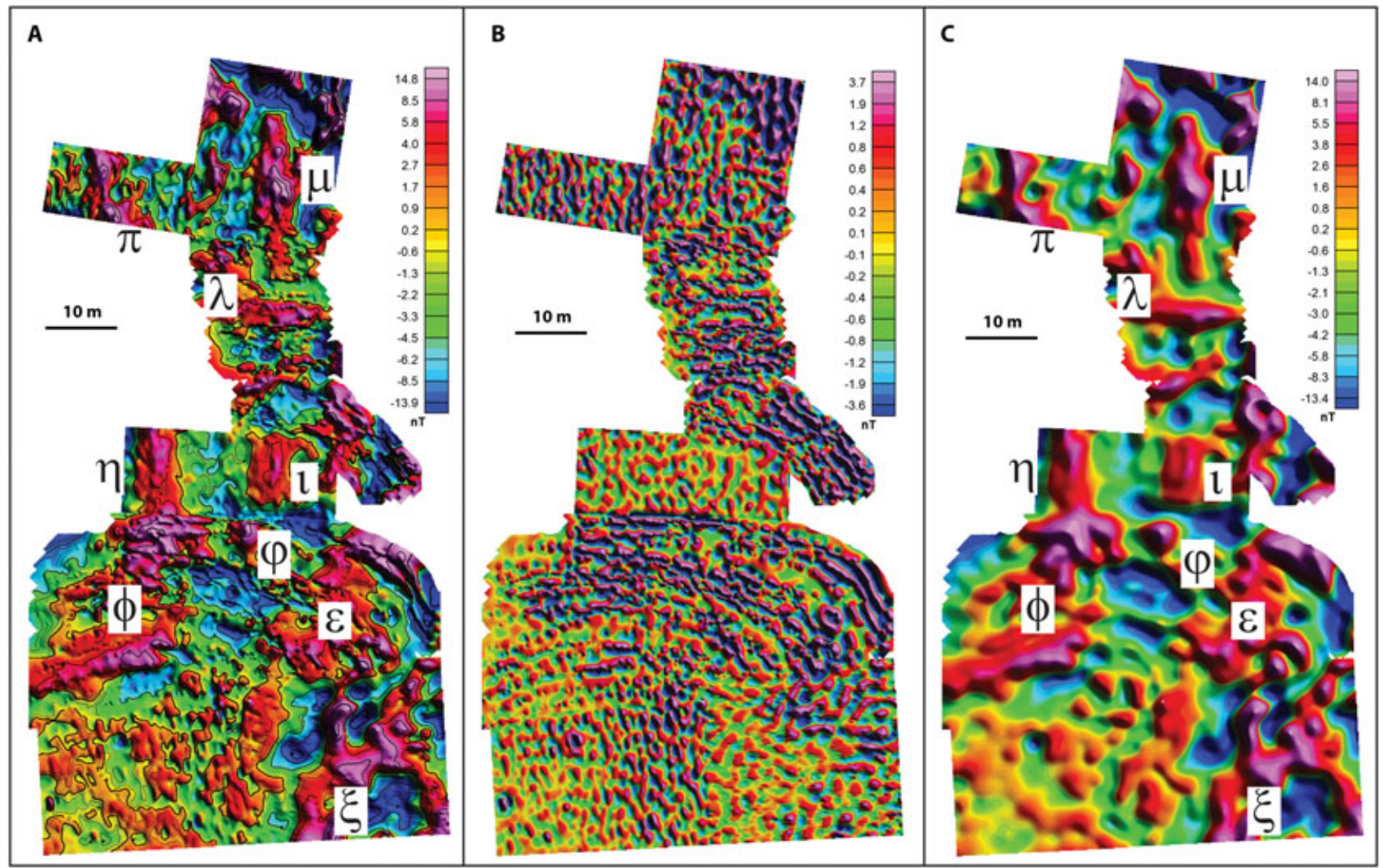

Figure 8. Combined magnetic anomaly map of sites $A-H(A)$. Panels $(B)$ and $(C)$ show the high-pass and low-pass filtered maps, respectively, with cutoff wavelength $\lambda \mathrm{c}=3 \mathrm{~m}$.

high-pass (HP) and low-pass (LP) filtered anomalies, in order to enhance features at different depths. Sector A02, which is very close to the Hellenistic walls, presents an apparently irregular long-wavelength pattern of positive anomalies (Figure 6C), possibly associated with the supply of external material after the 
collapse of the city walls. However, the HP-filtered map in Figure 6B shows that a regular arrangement of structures exists, which can be interpreted in terms of archaeological features. In particular, this map reveals the presence of a circular feature, $\alpha$, close to the eastern side, having a diameter of $\sim 10 \mathrm{~m}$. All the maps show a large $50 \mathrm{~m} \times 25 \mathrm{~m}$ roughly rectangular area, $\beta$, dominated by negative anomalies, which is bounded by strongly magnetized material (Figure 6). The HPfiltered image also reveals the presence of a more fine structure within the large rectangular area, with a regular arrangement of walls and rooms.

Magnetic anomalies for sector A01-A03-A04 are illustrated in Figure 7. This map suggests the presence of both radial and longitudinal structures that could support the existence of a buried theatre along this slope. In particular, the standard and the LP-filtered maps (Figure 7A, 7C) show very clearly the presence of a circular plate, $\gamma$, most likely made by calcareous material, which can be interpreted as an orchestra, while a central positive magnetic high could be associated with a thymele. Four evident radial positive anomalies, $\chi$, with amplitudes between 60 and $10 \mathrm{nT}$ point directly to the centre of the circular plate. It is unlikely that they are generated by radial arrangements of brick fragments or other baked materials. A more reasonable explanation for these anomalies is that they are associated with magnetically enriched topsoil (e.g. Fassbinder, 2015), possibly characterized by high concentration of pottery ash or burned material, which fills deep radial grooves of theatre klimakes. Other relevant anomalies, most probably generated by collapsed buildings, are visible in the upper part of these maps. They also include a $6 \mathrm{~m}$ large magnetic dipole, $\delta$, with a quite strong positive peak having $100 \mathrm{nT}$ magnitude. The longitudinal symmetry of buried features in this sector is more evident in the HP-filtered map (Figure 7B), which shows a dense circular alignment that could be interpreted as a theatre koilon. However, the possible presence of calcareous wedge-shaped seating sections (kerkides), $\mathrm{k}$, is well apparent on the standard and the LPfiltered maps (Figure 7A, 7C).

The last sector includes sites $\mathrm{A}-\mathrm{H}$ and is located along the western slope (Figure 8 ). In principle, this area could be a good candidate as a locus for the Antigonea theatre. However, both the unfiltered and the LP-filtered magnetic anomaly maps for this sector show smaller anomalies, with predominant orthogonal arrangement in the north-northeast-south-southwest/ north-northwest-south-southeast direction. The HPfiltered anomalies do not seem to reveal additional features. Figures $8 \mathrm{~A}$ and $8 \mathrm{C}$ include several positive anomalies that could be generated by brick walls, carbonate walls that incorporate fired or baked material, fired clay (e.g. roof tiles), or large accumulations of potsherds (anomalies $\eta, 1, \lambda, \varphi, \mu, \xi, \pi, \varepsilon$, and $\phi$ ). Finally, a $\sim 4 \mathrm{~m}$ large dipolar source, $\phi$, can be observed

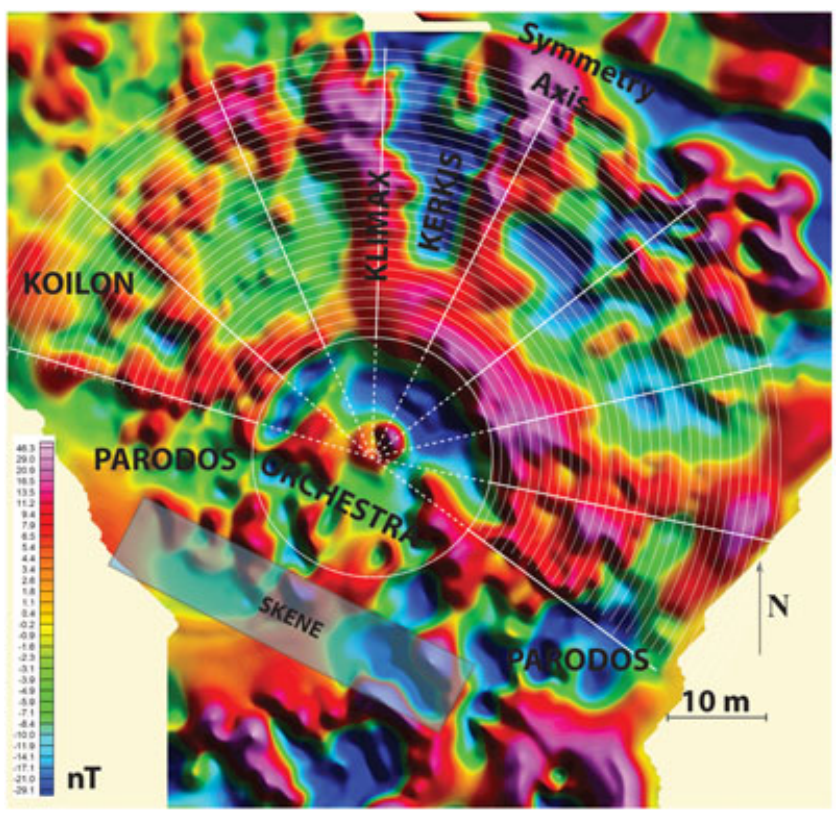

Figure 9. Interpretation of the radial and longitudinal pattern of the magnetic anomaly field at sites A01-A04, showing a possible location and geometry of the Antigonea theatre buried monumental buildings.

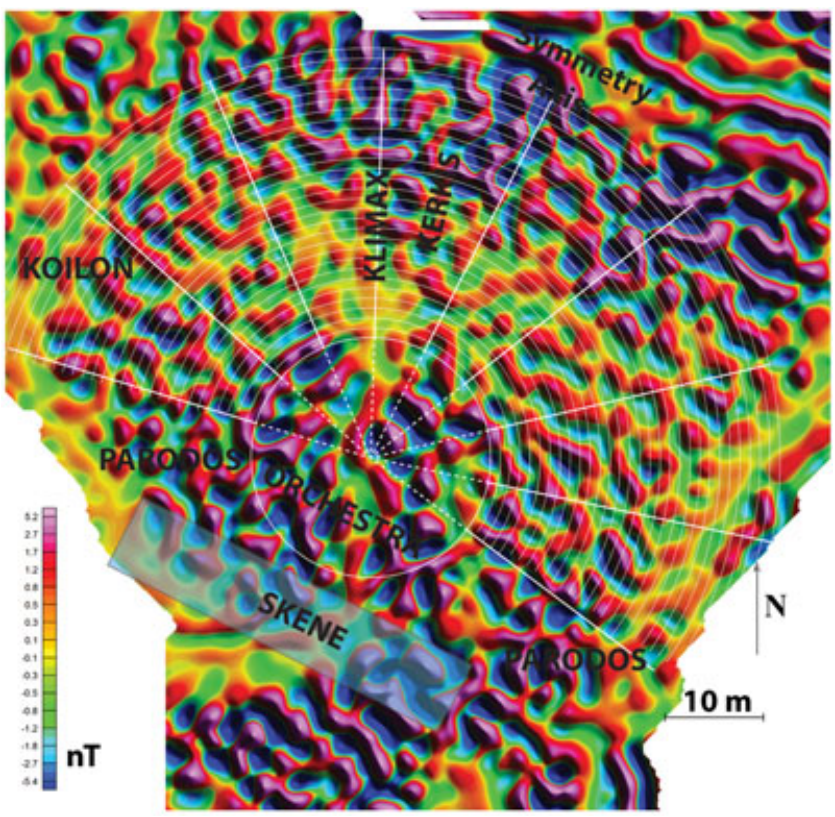

Figure 10. Interpretation of the radial and longitudinal pattern of the high-pass filtered magnetic anomaly field at sites A01-A04, showing a possible location and geometry of the Antigonea theatre buried monumental buildings. 
Searching for the Antigonea Theatre

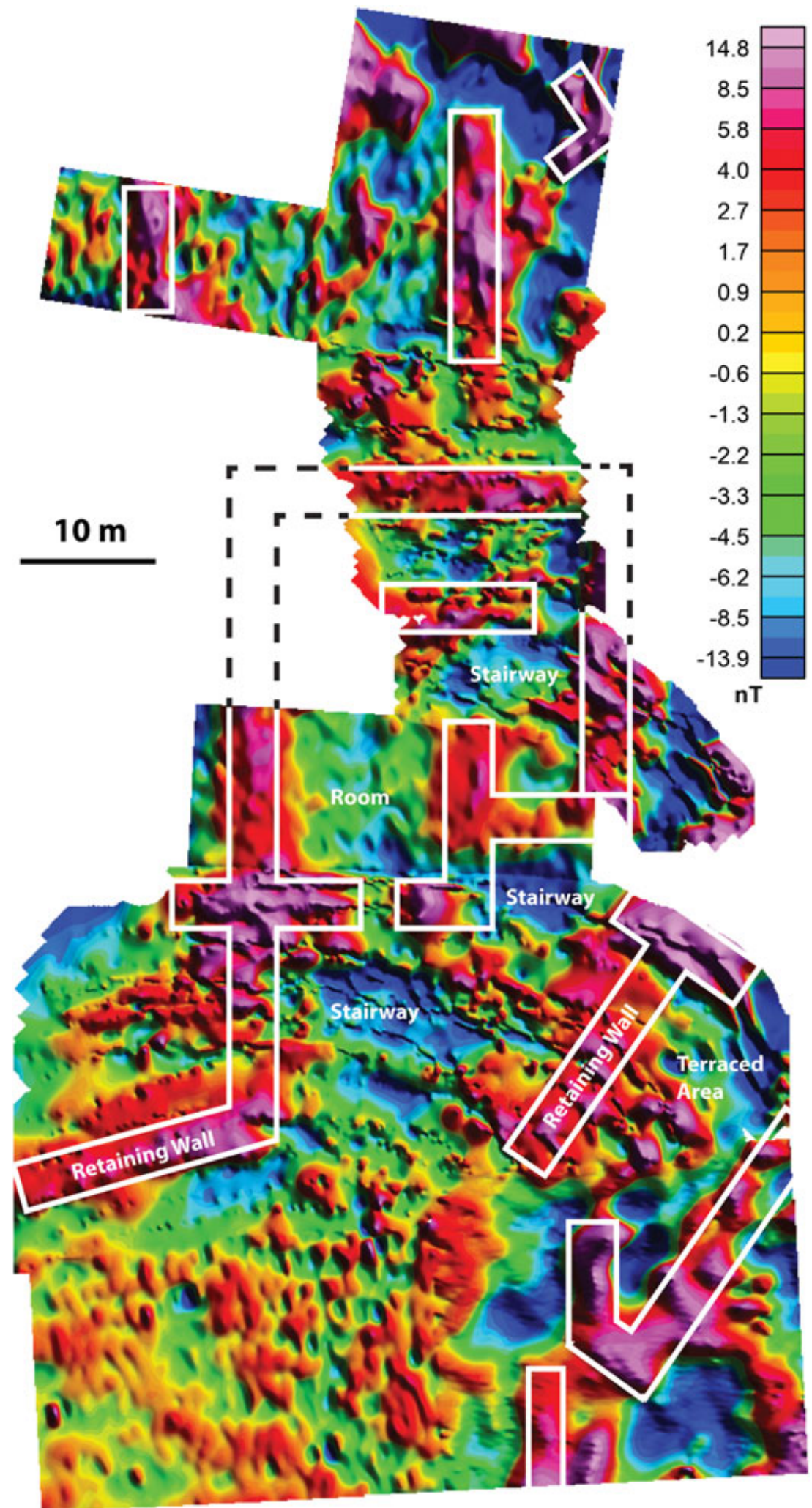

Figure 11. Archaeological interpretation of the magnetic anomaly field at sites $\mathrm{A}-\mathrm{H}$, showing location and geometry of the monumental buildings in this area. 
in the central area. This feature could be a mound of materials with strong susceptibility.

\section{Discussion}

The results presented in the previous section strongly support the possibility that a Hellenistic theatre is buried beneath the eastern concavo-concave slope along the southern side of the Jermë hill (Figure 5). The observed radial and longitudinal patterns of magnetic anomalies in this sector are indeed compatible with canonical construction schemes of Greek Hellenistic theatres (Vitruv. V, 7-9; Gros, 1997; Frederiksen, 2000). Interpretative maps of this pattern are shown in Figures 9 and 10. First, we checked if a system of circles existed, having the same centre of the circular structure $\gamma$ in Figure 7, which could provide an acceptable fit to the observed longitudinal pattern. Both Figures 9 and 10 show an excellent fit between the pattern of magnetic anomalies in this sector and circles about the centre of feature $\gamma$. According to this interpretation, the theatre koilon and orchestra would have a diameter of $\sim 80$ and $\sim 24 \mathrm{~m}$, respectively, thereby it could be considered as a medium-sized theatre according to the classification scheme of Rossetto and Sartorio (1994). The second step was to test if the observed radial structures could be part of a system of regularly disposed klimakes. We found that an angular klimax spacing of $25^{\circ}$ provided a satisfactory fit to the observed radial anomalies and to the unique clearly defined wedge-shaped kerkis area. This analysis also led to determine a total koilon angle of $200^{\circ}$ and the theatre symmetry axis, which resulted in a strike of $\mathrm{N} 26.9^{\circ} \mathrm{E}$ (Figure 9). This strike is orthogonal to the topographic contour lines in the upper part of the slope, in the interval $534-538 \mathrm{~m}$, whereas it cuts obliquely the contour lines in the lower area. This could be a consequence of increased accumulation rates and slope progradation along the orographic right, an interpretation that is supported by the shape of the contour lines. The available data do not allow us to rule out the presence of a summa cavea in the northernmost part of Figure 9 and of a proedria. The theatre seems to have only one centre, both for koilon and orchestra, as it occurs, for example, in the theatre of Priene (Neppi Modona, 1961; De Bernardi Ferrero, 1970) and in accordance with the Vitruvian models (Vitruv. 7. 1-2). Unfortunately, the area where the theatre skene could be found was not covered adequately by our measurements. Therefore, it is not possible to state if remains of this part of the theatre exist close to the southern side of the circular area $\gamma$, although the dominance of strongly negative anomalies could be interpreted as accumulation of carbonate material that formerly was part of the skene.

A structural interpretation of the magnetic anomalies observed along the western sector is illustrated in Figure 11. We note the presence of several structures and some dipoles along this sector (Figure 11). The structural pattern is complex and could be the result of a superposition of the signal associated with inplace features and the magnetic signal generated by materials that have been transported from upslope locations. Data analysis allows us to assume the presence of a number of terraces with retaining walls that, adapting to the morphology, organize the lower side of the slopes to the east and west of the investigated area. Along the western slope, a series of terraced structures, possibly connected by stairs, are organized around a big room of $20 \mathrm{~m} \times 15 \mathrm{~m}$.

\section{Conclusion}

In this paper, we have shown that magnetic evidence exists for the presence of a buried monumental theatre building along the eastern part of the southern Jermë hill slope, just outside the walls of Antigonea, a mysterious Hellenistic city that was probably founded by Molossian king Pyrrhus around 296 BC. In addition, other interesting buildings can be found along an adjacent area, supporting the possibility that the southern slope, with its road to the Drino Valley, was densely populated by edifices. A new survey technique was designed to collect magnetic data along concavoconcave slopes, which could minimize the field distortion caused by the terrain effect.

\section{Acknowledgements}

This work was partly funded by University of Camerino grants (FAR Schettino and FAR Pambianchi) and partly by University of Macerata and MAECI grants. The authors are grateful to the students that helped them in surveying the site and to the Albanian workers who contributed to the clearing of the survey area of underbrush. The authors also thank two anonymous reviewers for their suggestions. Finally, the authors are very grateful to Professor Marcello Ciminale for his valuable insights just before his demise.

\section{References}

Budina D. 1976. Antigonee d'Epire. Iliria 4: 327-346. 
Çondi D. 2014. Excavation in the ancient city of Antigonea. Proceedings of the International Congress of Albanian Archaeological Studies; 241-252.

De Bernardi Ferrero D. 1970. Teatri in Asia Minore III. L'erma di Bretschneider: Roma.

Eppelbaum LV, Khesin BE, Itkis SE. 2001. Prompt magnetic investigations of archaeological remains in areas of infrastructure development: Israeli experience. Archaeological Prospection 8(3): 163-185.

Fassbinder JW. 2015. Seeing beneath the farmland, steppe and desert soil: magnetic prospecting and soil magnetism. Journal of Archaeological Science 56: 85-95.

Frederiksen R. 2000. Typology of the Greek theatre building in late classical and hellenistic times. Proceedings of the Danish Institute at Athens 3(3): 135-175.

Gros P. 1997. Vitruvio. De Architectura. Einaudi Torino: Turin.

Hannam JA, Dearing JA. 2008. Mapping soil magnetic properties in Bosnia and Herzegovina for landmine clearance operations. Earth and Planetary Science Letters 274(3): 285-294.

Kangazian M, Oskooi B, Namaki L. 2015. Investigation of the topography effect on the shape and polarity of the magnetic anomalies. Bollettino di Geofisica Teorica ed Applicata 56(1): 43-54.

Khesin BE, Alexeyev VG, Eppelbaum L. 1996. Interpretation of Geophysical Fields in Complicated Environments. Springer Science \& Business Media: Berlin; 352.

Meço S, Aliaj S. 2000. Geology of Albania. Gebruder Borntrager: Berlin; 246.

Mitchell J. 2006. Strategies for salvation: the triconch church at Antigoneia and its mosaic pavement. In New Directions in Albanian Archaeology: Studies Presented to Muzafer Korkuti, Bejko L, Hodges R (eds). International Centre for Albanian Archaeology: Tirana; 261-276.

Neppi Modona A. 1961. Gli edifici teatrali greci e romani. Olschki editore: Firenze.

Perna R. 2013. Hadrianopolis (Sofratikë, Albania): monumental and economic Evolution. In Identity and
Connectivity, Bombardieri L, D'Agostino A, Orsi V, Guarducci G, Valentini S (eds), Proceedings of the 16th Symposium on Mediterranean Archaeology, Florence, Italy, 1-3 March 2012 (= BAR Int.Ser., 2581); 935-944.

Perna R. 2015. Caonia e Piceno: due modelli di occupazione del territorio in età romana a confronto. In Marion Y, Tassaux F (eds), AdriAtlas et l'histoire de l'espace adriatique du VIe s. a.C. au VIIIe s. p.C., Actes du colloque international de Rome, 4-6 November 2013; 305-335.

Perna R, Çondi D. 2012. Hadrianopolis II. Edipuglia: Bari.

Perna R, Çondi D. 2014a. Hadrianopolis e la valle del Drino: sviluppo monumentale ed economico dall'età ellenistica. In Perzhita L, Gjipali I, Xoxha G, Muka B (eds.), Proceedings of the International Congress of Albanian Archaeological Studies, Tirana, 21-22 November 2013; 367-386.

Perna R, Çondi D. 2014b. Hadrianopolis dhe në Luginën e Drinos: Raportit të Aktivitetit nga Misioni ItaloShqiptare - 2014 - Hadrianopolis e la valle del Drino: relazione sull'attività svolta dalla missione italo albanese - anno 2014., in Iliria 2014, XXXVII.

Rossetto PC, Sartorio GP. 1994. Theatre and theatres. Teatri greci e romani - Alle origini del linguaggio rappresentato I: 64-84.

Shary PA, Sharaya LS, Mitusov AV. 2002. Fundamental quantitative methods of land surface analysis. Geoderma 107(1): 1-32.

Tite MS, Linington RE. 1975. Effect of climate on the magnetic susceptibility of soils. Nature 256: 565-566.

Yaalon DH. 1997. Soils in the Mediterranean region: what makes them different? Catena 28(3): 157-169.

Zachos KL, Condi D, Pliakou G, Karatzeni V. 2006. The Antigoneia project: Premilinary report on the first season. In New Directions in Albanian Archaelogy: Studies Presented to Muzafer Korkuti, Bejko L, Hodges R (eds). International Centre for Albanian Archaelogy: Tirana; 379-443. 